\title{
Study of laser interaction in water flow confinement at high repetition rate
}

\author{
L. Berthe, ${ }^{\text {a) }}$ D. Courapied, S. El karnighi, P. Peyre, C. Gorny, and Y. Rouchausse \\ Lab. Procédés et Ingéniérie en Mécanique et Matériaux, UMR 8006, ENSAM/CNRS/CNAM, 151 Boulevard de \\ l'Hôpital, 75013 Paris, France
}

\begin{abstract}
This paper presents a study on the confined interaction with water flow for two successive laser pulses. The dynamic of the renewal of water films after shock produced by the laser is observed using a high speed camera. Pressure produced by the two pulses is measured from rear free surface velocity measurements using a velocimeter interferometry system for any reflector. The results show a threshold delay between the two laser pulses for which laser/target coupling of the second pulse decreases. This depends on the spot diameter, the laser intensity, and flow rate. This threshold can be calculated from the maximum jet diameter and flow rate. At an incident power density of $3 \mathrm{GW} / \mathrm{cm}^{2}$, a spot diameter of $1 \mathrm{~mm}$, and a flow rate of $10 \mathrm{~m} / \mathrm{s}$, the maximum repetition rate ensuring target/coupling of successive laser pulses can be $1 \mathrm{kHz}$. The results open perspective for laser shock peening at high repetition rates.
\end{abstract}

Key words: laser, plasma, shock, peening

\section{INTRODUCTION}

In the seventies, Anderholm ${ }^{1}$ and Clauer $^{2}$ have discovered the potential of shock produced by a laser in the confined regime to improve the mechanical properties of metallic surfaces. This industrial treatment is called "laser shock peening." ${ }^{\prime-6}$ Later, it has been demonstrated that the shock laser technique is promising for the adhesion test of coatings $^{7,8}$ and composite weak bond detection. ${ }^{9}$ Figure 1 shows the principle of the confined regime. The target is covered with a transparent layer to laser wavelength. The plasma is confined, and the maximum pressure is higher than that in the direct configuration. ${ }^{10}$

Since the work of these pioneers, water is preferred for confinement. It makes the contact between the surface target and material confinement for shaped parts and rough surfaces. Water flow renews the confinement layer between laser pulses and removes residual particles produced by laser ablation. This configuration opens treatment for high covering rates.

However, maximum pressure is limited due to breakdown plasma (occurring in water) screening the metallic target from the laser beam. ${ }^{11}$ Besides, the shock wave produced in water induces liquid jet toward the focusing lens for its protection. The best compromise for wavelength is the second harmonic of a NeoDymium-doped Yttrium Aluminium Garnet (Nd:YAG) laser at $532 \mathrm{~nm}$. It offers a more efficient confined interaction, a higher breakdown threshold, ${ }^{12}$ and the protection of the laser system against backreflection from the plasma.

Up to now, the repetition rate (RR) of multi-Joule laser beams is limited in the range of a few tens of hertz due to pumped lamp flash technologies. But the new generation of pumped diode lasers opens processes at kilohertz repetition rates. ${ }^{13,14}$ Nevertheless, these new technologies again question

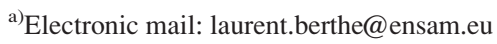

the capability of water flow to renew in time the state of the confinement pulse-by-pulse. Up to now, pressure measurements related to laser interactions in the water confinement regime were performed on individual pulses and static water ${ }^{1,10-12}$ due to the lack of the high repetition rate multiJoule laser for the range of power densities of the process $\left(1-10 \mathrm{GW} / \mathrm{cm}^{2}\right)$.

So, this paper presents a study of the influence of the delay between two pulses on the interaction in the water flow confinement regime reproducing configurations at a high

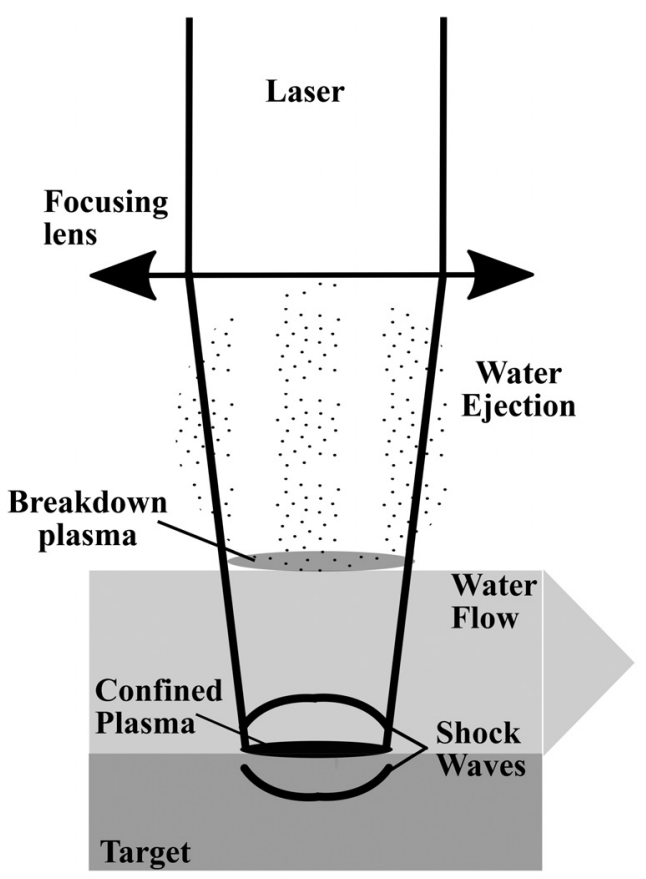

FIG. 1. Principle of the laser interaction in the water confinement regime with water flow. 
repetition rate. Recent paper ${ }^{15}$ studies the effect of the delay between two pulses in the confine regime in the range of nanoseconds. It concerns the new configuration for an adaptative laser adhesion test. In the present paper, the ms delay range corresponds to laser shock peening applications.

The experimental approach is based on a velocimeter interferometry system for any reflector (VISAR) measurements ${ }^{16}$ and direct observation using a high speed camera done with two successive laser pulses. Experiments focus on the delay between pulses, power densities, spot diameters, and water flows. Second part describes the experimental setup and methods. The third part presents the results and discussion demonstrating that an optimization of process parameters allows laser shock peening with future multikilohertz laser sources.

\section{EXPERIMENTAL SET-UP AND METHODS}

Figure 2 shows a schematic view of the experimental set-up performed with the Hephaestus facility at Lab PIMM.

The laser from Thales company delivers two collinear beams at a wavelength of $0.532 \mu \mathrm{m}$ with an adjustable energy up to $7 \mathrm{~J}$ and a delay up to $500 \mathrm{~ms} \pm 1 \mathrm{~ns}$. The pulse time shape is Gaussian with a full width at half maximum of $7 \mathrm{~ns}$. Beams are focused with a Plano-convex lens with a focusing length of $150 \mathrm{~mm}$. Spot diameters have been measured at the surface target using camera system imaging before experimental series (spot diameters of 1, 3, and $5 \mathrm{~mm}$ ). Energy (from few hundreds millijoules to $7 \mathrm{~J}$ ), impulsion time profile, and delay between two lasers are measured for each laser shot using an energy meter from Gentec company and photodiodes connected with an oscilloscope from Lecroy company.

The water flow velocity is measured using an off axis high speed (up to $2 \times 10^{4}$ images/s) camera from Photron company observing particles on its surface. This camera has observed the water flow ejection. An air cross-jet located at $20 \mathrm{~mm}$ from the surface expels water from the laser beam path.

Plasma pressure is measured from rear free surface velocity (RFSV) measurements on pure aluminum sheets by

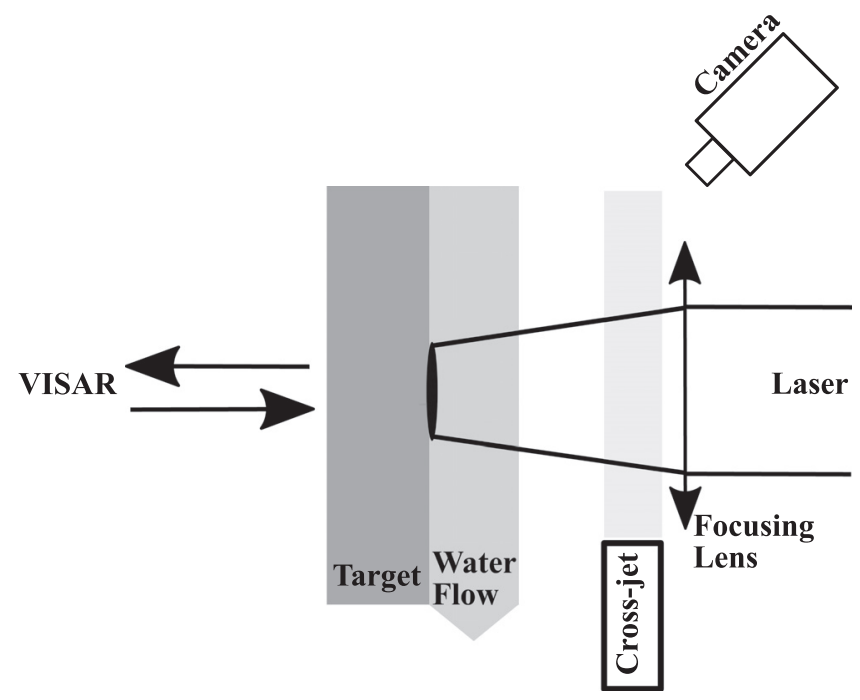

FIG. 2. Experimental set-up for the pressure measurement from RFSV measurements with VISAR in the water confinement regime with water flow.
VISAR. It has already been presented by Berthe $e t$ al. ${ }^{11}$ and Peyre et al. ${ }^{17}$ Due to the large scale time, delay (ms range) and pressure plasma (ns range) duration, between two pulses, measurements are separately performed for each pulse.

Figures 7(a) and 7(b) present typical time resolved profiles of rear free surface velocity (RFSV) measurements for first and second pulses at an incident power density of $3 \mathrm{GW} /$ $\mathrm{cm}^{2}$ and a spot diameter of $1 \mathrm{~mm}$. The delay between the two pulses is $20 \mathrm{~ms}$ or an equivalent repetition rate of $50 \mathrm{~Hz}$. For all profiles, the first peak corresponds to the first emergence at the rear surface of the shock wave produced at the front surface by the laser. The second peak corresponds to the emergence of the shock wave after its round propagation inside the target. We can determine plasma pressure generated by the laser by using

$$
P_{\max }=\rho_{o}\left(C_{o}+s \frac{u_{\text {free }}}{2}\right) \frac{u_{\text {free }}}{2}+\frac{1}{3} \sigma+\delta P,
$$

where $\rho_{o}$ is the bulk density of the target, $C_{o}$ is the bulk sound velocity, and $u_{\text {free }}$ is the rear free surface velocity. It is taken at the maximum of the first peak on the RFSV profile. $\sigma$ is the static yield stress, and $\delta P$ is the attenuation of the shock wave through the target. It is determined from pressure measurements with different thicknesses at the same intensity: $200,300,500$, and $1000 \mu \mathrm{m} .{ }^{17}$ So, plasma pressure measurements are independent of the target thickness for comparison with previous results. Table I presents mechanical parameters used for pure $\mathrm{Al}$ in this study. ${ }^{11}$

\section{RESULTS AND DISCUSSION}

\section{A. Maximum pressure with a unique pulse}

Figure 3 presents peak pressures as a function of incident power density for a unique laser pulse. They are determined from RFSV measurements for 200, 300, 500, and $1000 \mu \mathrm{m}$ $\mathrm{Al}$ sheets and Eq. (1). Curves can be separated into two main parts. Up to $8 \mathrm{GW} / \mathrm{cm}^{2}$, pressure increases with incident power density typically from $2 \mathrm{GPa}$ at $2 \mathrm{GW} / \mathrm{cm}^{2}$ to $5.5 \mathrm{GPa}$ at $8 \mathrm{GW} / \mathrm{cm}^{2}$. In this part, experiments are in agreement with Fabbro's Model ${ }^{10}$ giving peak plasma pressure by

$$
P_{\max }=\sqrt{\frac{\alpha}{2 \alpha+3} Z I_{\max }}
$$

where $2 / Z=\left(1 / Z_{\text {water }}\right)+\left(1 / Z_{\mathrm{Al}}\right)$, with $Z_{\text {water }}$ and $Z_{\mathrm{Al}}$ being the mechanical impedance of water and the Al target, respectively. $I_{\max }$ is the incident laser peak power density, and $\alpha$ is the fraction of internal energy devoted to plasma heating $\left(Z_{\text {water }}\right.$ $=0.165 \times 10^{-6} \mathrm{~g} \mathrm{~cm}^{-2} \mathrm{~s}^{-1}$ and $Z_{\mathrm{Al}}=1.48 \times 10^{-6} \mathrm{~g} \mathrm{~cm}^{-2} \mathrm{~s}^{-1}$ and $\alpha=0.4$ ).

TABLE I. Physical and mechanical property value for $\mathrm{Al}$ targets used in equation 1.

\begin{tabular}{lc}
\hline \hline$\rho_{o}\left(\mathrm{Kg} \mathrm{m}^{-3}\right)$ & 2700 \\
$C_{o}(\mathrm{~m} / \mathrm{s})$ & 5390 \\
$S$ & 1.34 \\
$\sigma(\mathrm{GPa})$ & 0.2 \\
\hline \hline
\end{tabular}




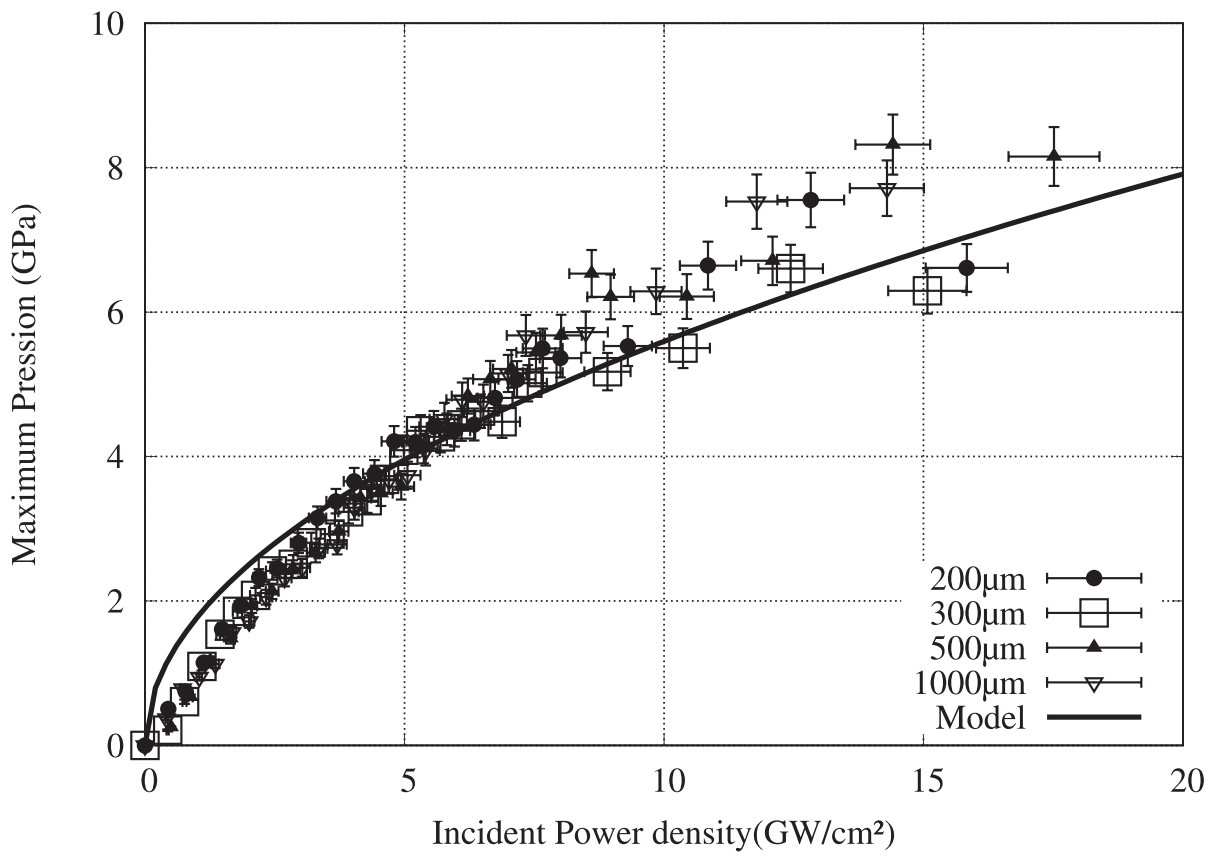

FIG. 3. Peak pressure as a function of incident power density in the water confinement regime (pulse duration: $7 \mathrm{~ns}$ ) determined from the RFSV measurement for Al target thicknesses of 200, 300, 500, and $1000 \mu \mathrm{m}$. Comparison with the Model (Ref. 10) using $\alpha=0.4$.

In this part, the model and experiments are in agreement with previous measurements. ${ }^{12}$ Above $8 \mathrm{GW} / \mathrm{cm}^{2}$, peak pressure is limited and scattered between 6 and $8 \mathrm{GPa}$. This effect is due to plasma breakdown in water which absorbs the incident beam. ${ }^{12}$ But the saturation threshold is higher $\left(8 \mathrm{GW} / \mathrm{cm}^{2}\right)$ than the previous one $\left(5-6 \mathrm{GW} / \mathrm{cm}^{2}\right)$ at the same wavelength. ${ }^{12}$ However, the pulse duration is different: $25-30 \mathrm{~ns}$ in Ref. 11 against $7 \mathrm{~ns}$ in the present work. The effect of the pulse duration has already been studied in the confined regime. It has been demonstrated that the pressure saturation threshold is lower with long pulses ${ }^{18}$ which favor ionization by electron avalanche. ${ }^{19}$

Measurements with thicknesses of 200, 300, 500, and $1000 \mu \mathrm{m}$ are consistent, validating the method and the model of shock wave attenuation in $\mathrm{Al}$.

Measurements with the two pulses require thicker sheets. Indeed, VISAR measurements require the target that is not deformed after the first pulse so that the laser probe remains self-collimated. This is possible only with 500 and $1000 \mu \mathrm{m}$ foils. Besides, for next discussions with two pulses, incident power densities are chosen below the saturation threshold, ensuring no breakdown plasma in the water flow $(1,2$, and $3 \mathrm{GW} / \mathrm{cm}^{2}$ ).

\section{B. Observation using a high speed camera}

Figure 4 shows some images taken using a high speed camera running at 5000 images/s (time integration is $10 \mu \mathrm{s}$ ) of the laser interaction confined by water flow with two pulses delayed with equivalent RR values of 50 and $200 \mathrm{~Hz}$. The incident power density is $3 \mathrm{GW} / \mathrm{cm}^{2}$, and the spot diameter is $3 \mathrm{~mm}$. In the figure, the $\mathrm{Al}$ target is on the left, laser beams come from the right, and water flows (surface velocity: $1 \mathrm{~m} / \mathrm{s}$ ) from the top. $t_{0}$ (Figs. 4(a) and 4(e)) corresponds to the time arrival of the first pulse.
For both the repetition rates, at $t_{0}$, strong ejection of water is observed. The time integration does not allow us to measure jet velocity.

$t_{0}=5 \mathrm{~ms}$ (Figs. 4(b) and 4(e)) corresponds to the time arrival of the second pulse at $200 \mathrm{~Hz}$. However, there are water jets and droplets along the laser path which screened the target as the image at $50 \mathrm{~Hz}$ shows. (The time arrival of the second pulse is $20 \mathrm{~ms}$ at $50 \mathrm{~Hz}$.)

At $t_{0}=19 \mathrm{~ms}$ (Figs. 4(c) and $4(\mathrm{~g})$ ), the water flow is already stabilized and there are no visible droplet clouds in the laser beam path. $t_{0}=20 \mathrm{~ms}$ (Fig. 4(d)) corresponds to the arrival of the second pulse at $50 \mathrm{~Hz}$. The interaction in the confined regime occurs in the nominal configuration with the water layer. The water flow has recovered the target surface with a new layer.

Figure 5 shows some images taken using a high speed camera running at $20000 \mathrm{image} / \mathrm{s}$ (time integration $10 \mu \mathrm{s}$ ) of the laser interaction confined by water flow with one pulse at incident power densities of 1 and $3 \mathrm{GW} / \mathrm{cm}^{2}$ and a spot diameter of $1 \mathrm{~mm}$. $t_{0}$ (Figs. 5(a) and 5(d)) corresponds to the first image after the first laser pulse. The water jet shape is different according to the laser intensity. At $3 \mathrm{GW} /$ $\mathrm{cm}^{2}$, as shown in Fig. 4, the expansion of the confined plasma extends up to a maximum diameter $\left(\phi_{j e t}\right)$ of $8 \mathrm{~mm}$. It demonstrates the lateral expansion of the plasma which breaks the water layer.

At $1 \mathrm{GW} / \mathrm{cm}^{2}$, the shape can be separated into two parts: an emerging water jet from the middle of a saucer shape. The jet corresponds to the ejection of the water column above the irradiated area. The saucer shape corresponds to the water film raised by the lateral expansion of the plasma. Pressure is lower than that for $3 \mathrm{GW} / \mathrm{cm}^{2}$. So, the entire surface of the water film is not broken. In these conditions, the renewal of the water film by the flow takes less time: $3.3 \mathrm{~ms}$ at $1 \mathrm{GW} /$ 


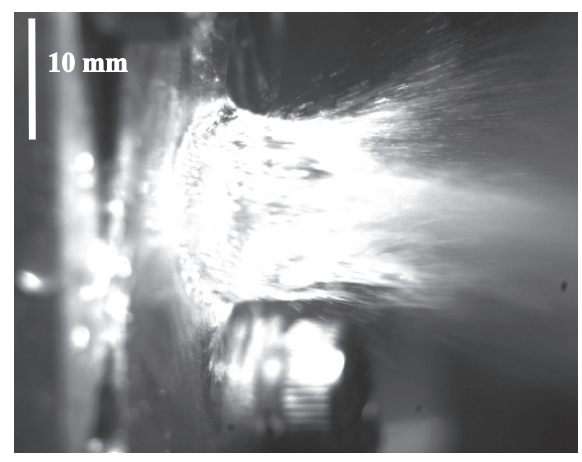

(a)

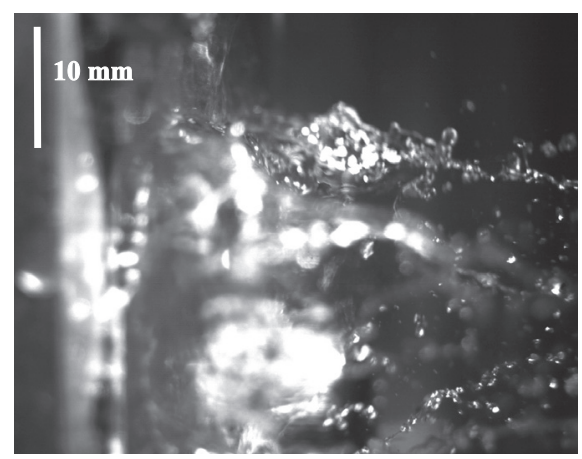

(b)

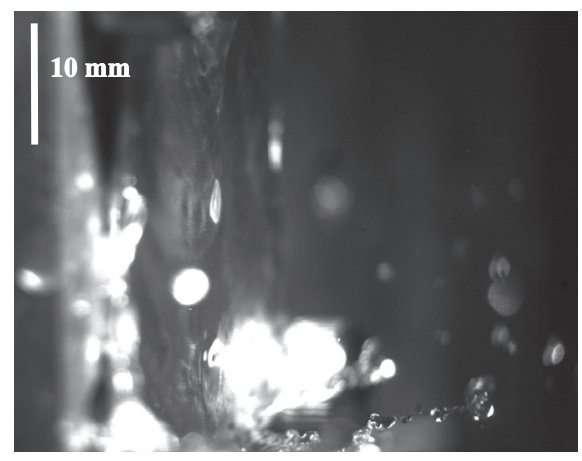

(c)

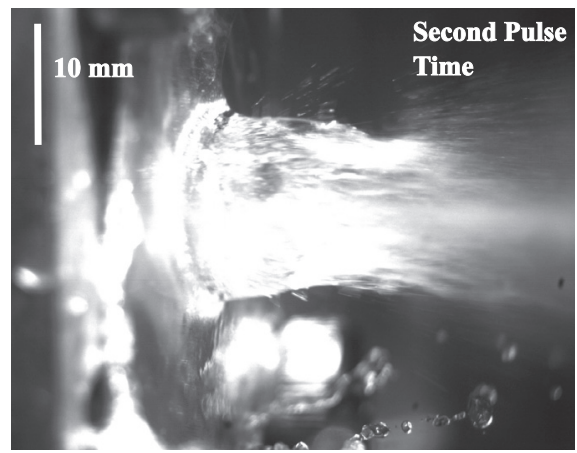

(d)

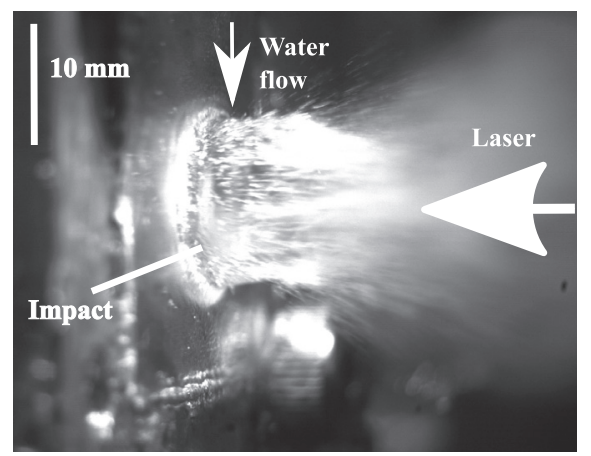

(e)

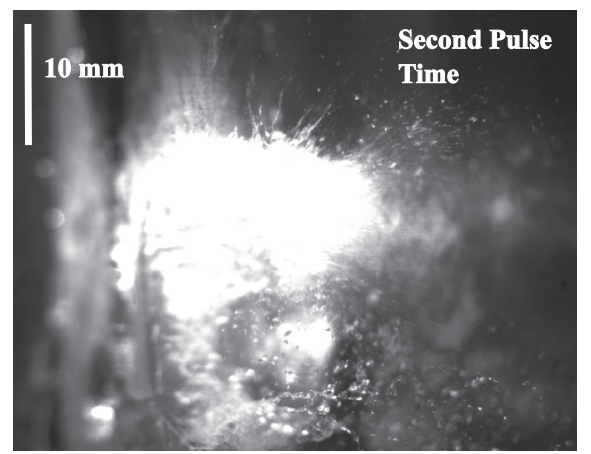

(f)

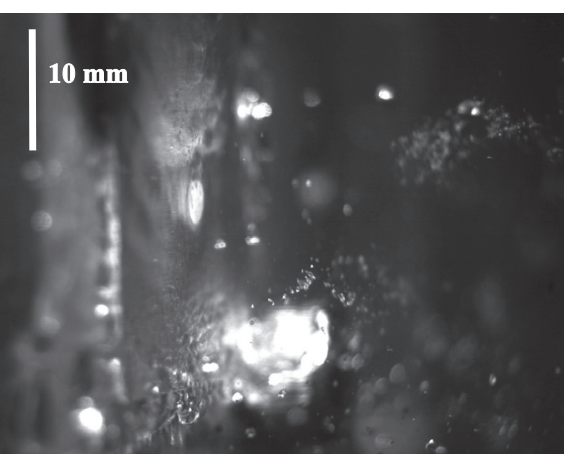

(g)

FIG. 4. Images extracted from the high-speed video (5000 images/s) of water ejection for two laser pulses in the water confinement regime at equivalent repetition rates of $50 \mathrm{~Hz}\left((\mathrm{a}) t=t_{0}\right.$, (b) $t=t_{0}+5 \mathrm{~ms}$, (c) $t=t_{0}+19 \mathrm{~ms}$, and (d) $t=t_{0}+20 \mathrm{~ms}$ ) and $200 \mathrm{~Hz}\left((\mathrm{e}) t=t_{0}\right.$, (f) $t=t_{0}+5 \mathrm{~ms}$, and (g) $t=t_{0}+19 \mathrm{~ms}$ ). The incident power density is $3 \mathrm{GW} / \mathrm{cm}^{2}$, and the spot diameter is $3 \mathrm{~mm}$. Surface flow rate: $1 \mathrm{~m} / \mathrm{s}$.

$\mathrm{cm}^{2}$ and $5.3 \mathrm{~ms}$ at $3 \mathrm{GW} / \mathrm{cm}^{2}$. Indeed, the water layer falls to close the interface between the target and water.

$F_{\text {flow }}$ is the frequency corresponding to the time to recover the surface of the water jet produced by the first pulse with a flow rate of $V_{\text {water }}$. It corresponds to the maximum repetition rate of the laser to ensure confinement. It can be evaluated from $\phi_{\text {jet }}$ measured from the High speed camera images and surface flow rate 


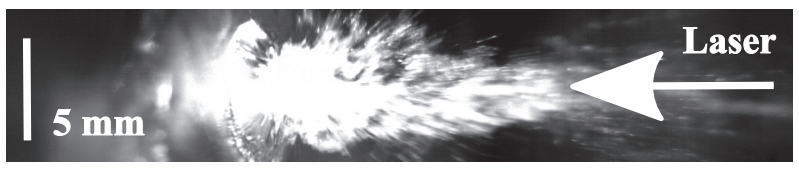

(a)

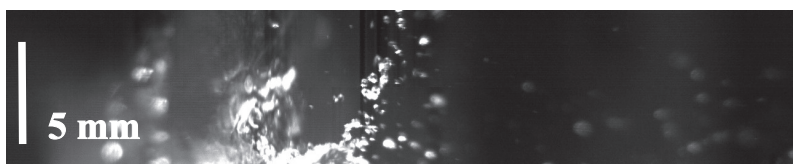

(b)

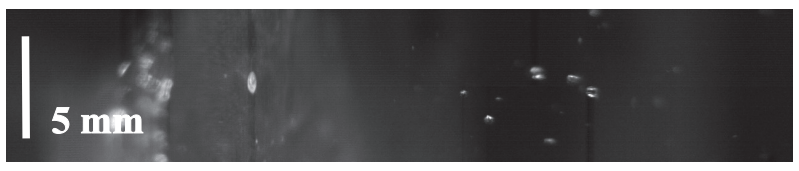

(c)

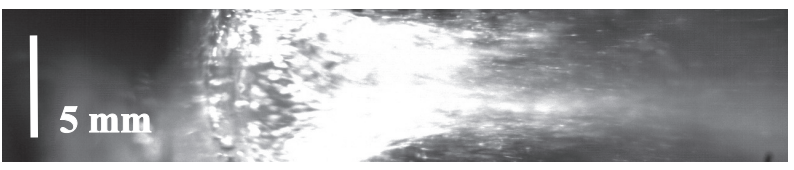

(d)

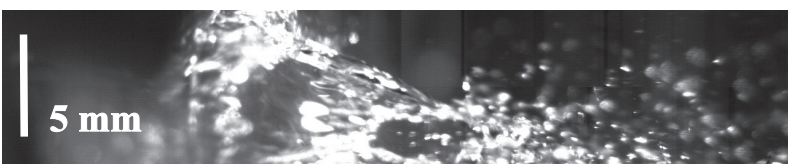

(e)

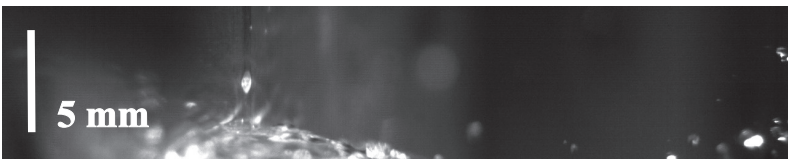

(f)

FIG. 5. Images extracted from the High-speed video (20000 images/s) of water ejection for incident power densities of $1 \mathrm{GW} / \mathrm{cm}^{2}\left((\mathrm{a}) t=t_{0}\right.$, (b) $t=t_{0}+2.2 \mathrm{~ms}$, and (c) $\left.t=t_{0}+5.5 \mathrm{~ms}\right)$ and $3 \mathrm{GW} / \mathrm{cm}^{2}\left((\mathrm{~d}) t=t_{0}\right.$, (e) $t=t_{0}+2.2 \mathrm{~ms}$, and (f) $\left.t=t_{0}+5.5 \mathrm{~ms}\right)$ and a spot diameter of $1 \mathrm{~mm}$. The surface flow rate is $1 \mathrm{~m} / \mathrm{s}$.

$$
F_{\text {flow }}=\frac{V_{\text {water }}}{\phi_{\text {jet }}}
$$

Table II shows the calculation for different configurations. $F_{\text {flow }}$ increases for the smallest spot diameters and the lowest laser intensity. For example, at $3 \mathrm{GW} / \mathrm{cm}^{2}$, it is 71 and $47 \mathrm{~Hz}$ for spot diameters of 3 and $5 \mathrm{~mm}$, respectively. For a spot diameter of $1 \mathrm{~mm}$, it is $125 \mathrm{~Hz}$ at $3 \mathrm{GW} / \mathrm{cm}^{2}$ and 284 at $1 \mathrm{GW} / \mathrm{cm}^{2}$. For a given water flow, it is faster to renew the smaller area produced by low incident power density and small spot diameters.

\section{Pressure measurements with two pulses}

\section{Influence of the spot diameter}

The screening of the target by the water jet and droplets produced by the first pulse has an influence on pressure induced by the second one. For example, Fig. 6 shows the pressure ratio (PR of peak pressure of the second pulse by the first one) as a function of equivalent repetition rate for three spot diameters $(1,3$, and $5 \mathrm{~mm})$ at $3 \mathrm{GW} / \mathrm{cm}^{2}$ and corresponding fits. The flow rate is $1 \mathrm{~m} / \mathrm{s}$.

TABLE II. Summary of the repetition rate threshold for which the pressure induced by the second pulse decreases $F_{\text {pressure }}$, determined from pressure measurements, and $F_{\text {flow }}$, the frequency corresponding to the time to recover the surface of the water jet produced by the first pulse with the flow rate from Eq. (3) and the high speed camera visualization experiment.

\begin{tabular}{lccccc}
\hline \hline $\begin{array}{l}\text { Spot diameter } \\
(\mathrm{mm})\end{array}$ & $\begin{array}{c}\text { Jet size } \\
(\mathrm{mm})\end{array}$ & $\begin{array}{c}\text { Surface flow rate } \\
(\mathrm{m} / \mathrm{s})\end{array}$ & $\begin{array}{c}\text { Power density } \\
\left(\mathrm{GW} / \mathrm{cm}^{2}\right)\end{array}$ & $\begin{array}{c}F_{\text {flow }} \\
(\mathrm{Hz})\end{array}$ & $\begin{array}{c}F_{\text {pressure }} \\
(\mathrm{Hz})\end{array}$ \\
\hline 5 & 21 & 1 & 3 & 47 & 80 \\
3 & 14 & 1 & 3 & 71 & 80 \\
1 & 8 & 1 & 3 & 125 & 190 \\
1 & 8 & 1 & 2 & 125 & 190 \\
1 & 3.5 & 1 & 1 & 284 & 300 \\
1 & 8 & 10 & 3 & 1250 & 100 \\
\hline \hline
\end{tabular}

Experimental data can be separated into two parts. In the first part, the PR is constant for the lowest repetition rates, and in the second one, PR decreases for the highest repetition rates. Clearly, in this part, the target is not covered by the water layer. Consequently, the laser/target coupling is not efficient in producing high pressure plasma. $F_{\text {pressure }}$ can also identified as the equivalent repetition rate threshold from which PR decreases.

$F_{\text {pressure }}$ decreases when the spot diameter increases. It is 190 for a spot diameter of $1 \mathrm{~mm}$ and $80 \mathrm{~Hz}$ for spot diameters of 3 and $5 \mathrm{~mm}$, respectively. For a given flow rate, the time to recover the surface and to discharge water cloud from the laser beam path after the first pulse is longer for larger spot diameters.

Table II shows that $F_{\text {pressure }}$ is in agreement with $F_{\text {flow }}$. It shows that rough evaluation using Eq. (3) can design the process parameters for laser shock peening applications at high

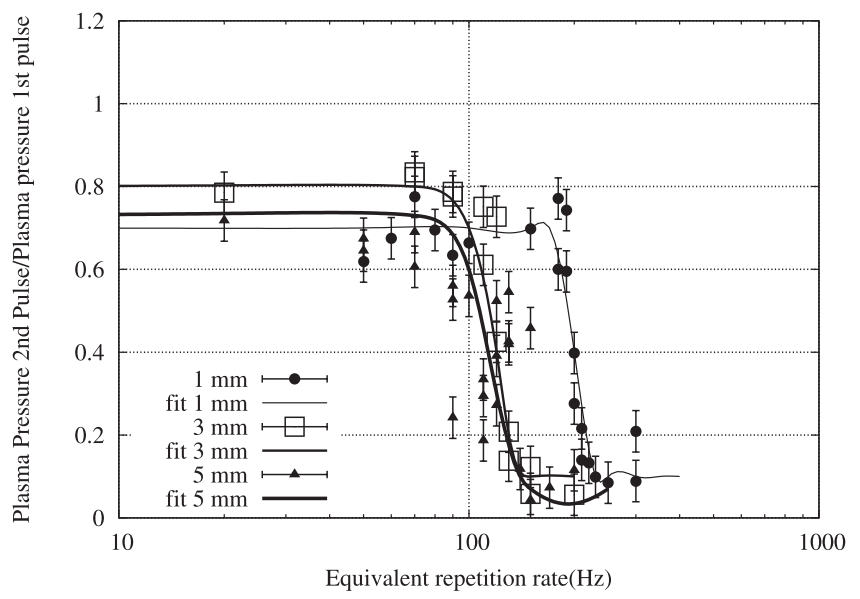

FIG. 6. Pressure ratio between the peak pressure of the second pulse and the first one as a function of delay between two pulses (given at an equivalent repetition rate) and spot diameters of 1,3 , and $5 \mathrm{~mm}$. The power density is $3 \mathrm{GW} / \mathrm{cm}^{2}$. The flow rate surface is $1 \mathrm{~m} / \mathrm{s}$. 


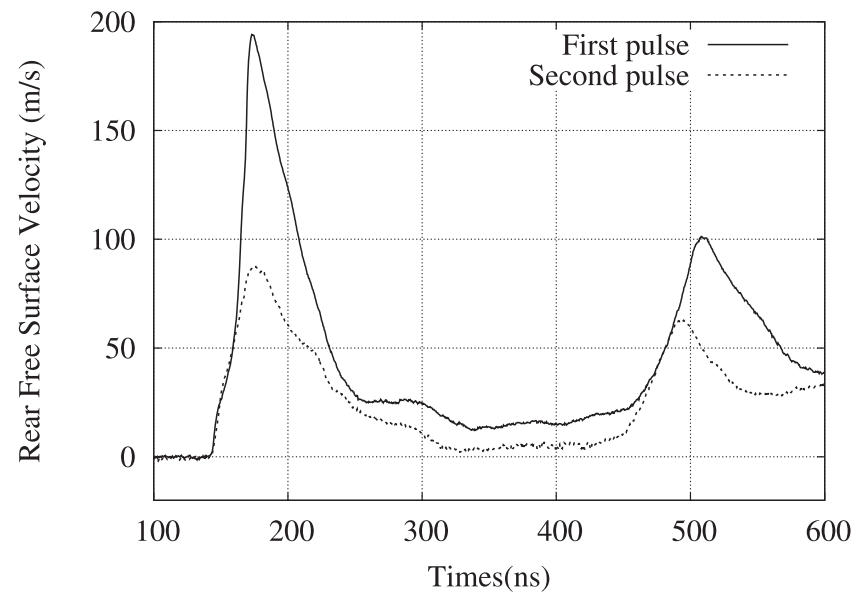

(a)

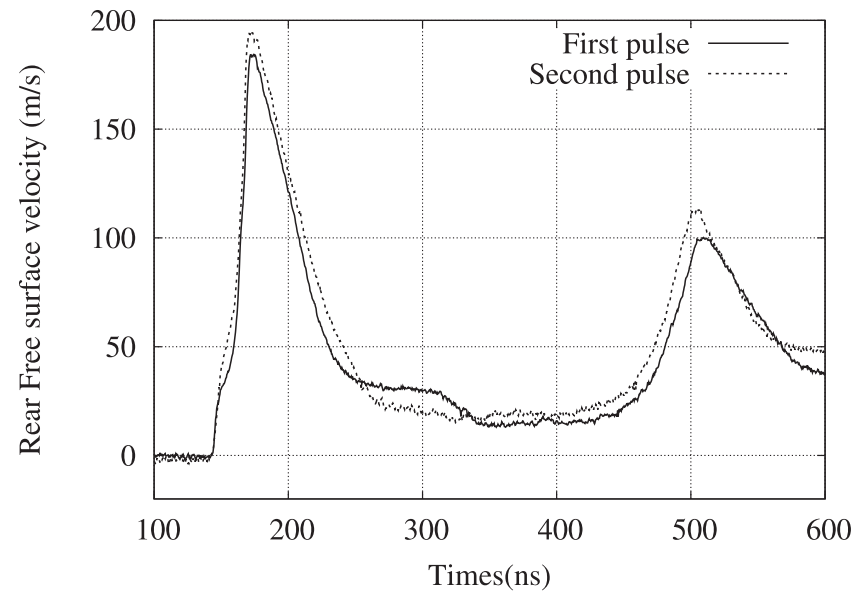

(b)

FIG. 7. Typical RFSV measurements by VISAR at $3 \mathrm{GW} / \mathrm{cm}^{2}$. The spot diameter is $1 \mathrm{~mm}$, and the equivalent repetition rate is $50 \mathrm{~Hz}$. (a) Without the cross-jet and (b) With the cross-jet.

repetition rates. Differences could be due to friction at the water target interface and surface tension.

\section{Influence of the cross-jet}

The level of constant PR in the lowest range of RR is only $0.7+0.1$ in Fig. 6 . It could be related to the interaction between the laser and the droplet cloud produced by the first laser pulse in the path of the beam. The laser beam could be diffused and absorbed by the water droplet cloud. Besides, detrimental plasma breakdowns can occur and absorb incident laser beam limiting plasma pressure. To evaluate crossjet efficiency, Fig. 7 compares RFSV with the cross-jet (a) and without the cross-jet (b) for the first and second pulses at an equivalent repetition rate of $50 \mathrm{~Hz}$ and the same conditions of image sequences as in Fig. 4. Clearly, the first velocity peak of the second pulse $(80 \mathrm{~m} / \mathrm{s})$ is lower than the half of the one induced by the first pulse $(200 \mathrm{~m} / \mathrm{s})$ when there is no cross-jet figure (Fig. 4(a)). When the cross-jet is efficient, first and second pulses generate the same pressure as in Fig. 7(b). Clearly, in experiments which provided the results shown in Fig. 6, water is not completely expelled by the air cross-jet from the first to second pulses.

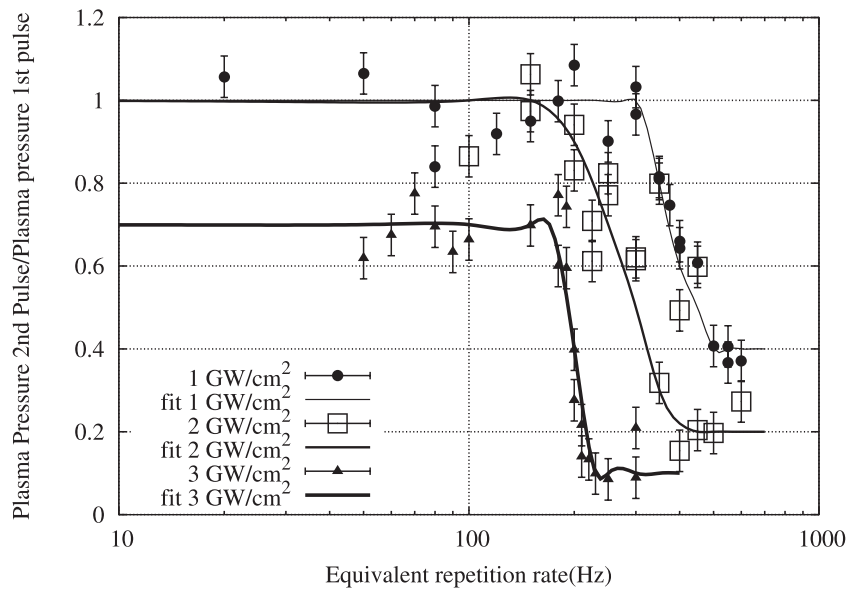

FIG. 8. Pressure ratio between the peak pressure of the second pulse and the first one as a function of delay between two pulses (given at an equivalent repetition rate) and incident power densities of 1,2 , and $3 \mathrm{GW} / \mathrm{cm}^{2}$. The spot diameter is $1 \mathrm{~mm}$. The water flow is $1 \mathrm{~m} / \mathrm{s}$.

\section{Influence of Incident laser power density}

Figure 8 shows the PR as a function of the equivalent repetition rate for three power densities $\left(1,2\right.$, and $\left.3 \mathrm{GW} / \mathrm{cm}^{2}\right)$ and corresponding fits. The spot diameter is $1 \mathrm{~mm}$. Graphs are also separated into two main parts as shown in Fig. 6. However, $F_{\text {pressure }}$ values are different: 190 at 2 and $3 \mathrm{GW} /$ $\mathrm{cm}^{2}$ and $300 \mathrm{~Hz}$ at $1 \mathrm{GW} / \mathrm{cm}^{2}$. This influence is in agreement with the direct observation using the high speed camera, showing that the water jet due to plasma expansion is little larger at the lowest incident laser power densities.

\section{Influence of the flow rate}

Figure 9 presents the PR as a function of the equivalent repetition rate for two water flow rates of 1 and $10 \mathrm{~m} / \mathrm{s}$ and corresponding fits. The spot diameter is $1 \mathrm{~mm}$. The incident power density is $3 \mathrm{GW} / \mathrm{cm}^{2}$. Clearly, $F_{\text {pressure }}$ is higher with the highest flow rate, which renews faster the water layer. It is 190 at $1 \mathrm{~m} / \mathrm{s}$ against $1000 \mathrm{~Hz}$ at $10 \mathrm{~m} / \mathrm{s}$. The result is in agreement with the evaluation of $F_{\text {flow }}$ from Eq. (3). For the

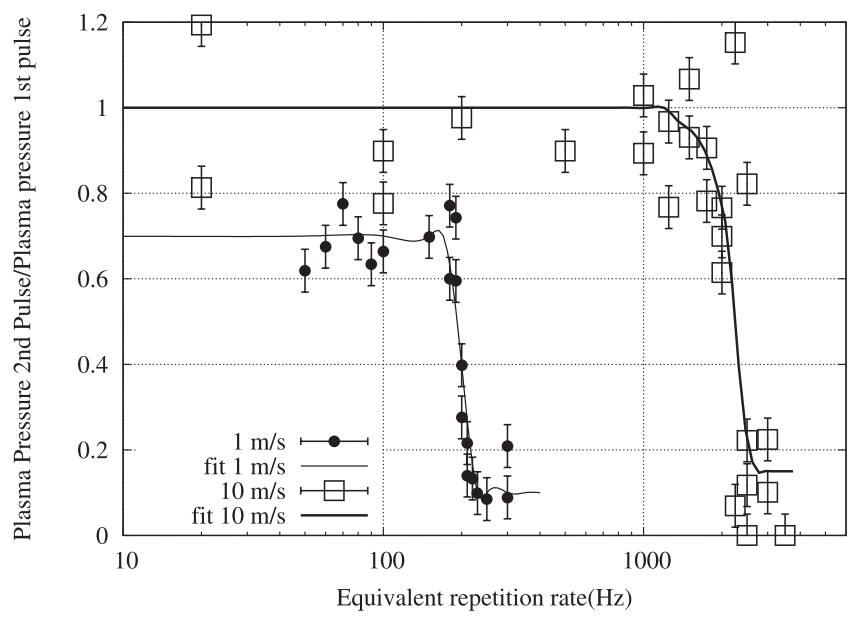

FIG. 9. Pressure rate between the peak pressure of the second pulse and the first one as a function of delay between two pulses (given at an equivalent repetition rate) for two surface flow rates of 1 and $10 \mathrm{~m} / \mathrm{s}$. The spot diameter is $1 \mathrm{~mm}$, and the incident power density is $3 \mathrm{GW} / \mathrm{cm}^{2}$. 
lowest repetition rate, pressure produced by second laser pulses can be higher than the one generated by the first one $(P R>1)$. Clearly, at the flow rate of $10 \mathrm{~m} / \mathrm{s}$, the water film cannot be stable. Also, ruptures at the water/target interface can occur during one and/or both the laser pulses which do not ensure confinement. Also, the second pulse may in some cases produce higher pressure than the first pulse.

\section{SUMMARY}

This paper presents the direct observation of the dynamics of water flows during the interaction in water confinement with two laser pulses delayed in the ms range. The maximum pressure produced (measured using VISAR diagnostic) by the two pulses is compared as a function of spot diameter, incident laser intensity, and flow rates. The maximum repetition rate allowing the renewal of the water layer can be evaluated using the simple relation between the flow rate and the maximum jet diameter measured from high speed camera images (Eq. (2)). It is in agreement with pressure measurements, showing a strong decrease for the highest repetition rate. In any case, the results show that repetition rates up $1 \mathrm{kHz}$ can be reached opening the future laser shock peening process. Further works will concern the predictive approach of the maximum jet area and the maximum flow rate in relation to the surface shape to be processed and the optimization of ablative coating applied to protect the surface from detrimental thermal effects in these new ranges of parameters.

\section{ACKNOWLEDGMENTS}

The author acknowledges the French National Agency for Research (ARCOLE ANR-12-BS09-0009) and the Region Île-de-France (SESAME Hephaistos).

${ }^{1}$ N. Anderholm, "Laser generated stress waves," Appl. Phys. Lett. 16, 113-115 (1970).

${ }^{2}$ B. Fairand, A. Clauer, R. Jung, and B. Wilcox, "Quantitative assessment of laser-induced stress waves generated at confined surfaces," Appl. Phys. Lett. 25, 431-433 (1974).

${ }^{3}$ N. B. Dahotre and S. P. Harimkar, Laser Fabrication and Machining of Materials (Springer Science + Business Media, LLC, New York, 2008), p. 477.
${ }^{4}$ A. H. Clauer, J. H. Holbrook, and B. P. Fairand, Shock Waves and HighStrain-Rate Phenomena in Metals (Plenum Press, New York and London, 1981), pp. 675-702.

${ }^{5} \mathrm{P}$. Peyre and R. Fabbro, "Laser shock processing: a review of the physics and applications," Opt. Quantum Electron. 27, 1213-1229 (1995).

${ }^{6}$ Y. Sano, N. Mukai, K. Okazaki, and M. Obata, "Residual stress improvement in metal surface by underwater laser irradiation," Nucl. Instrum. Methods Phys. Res., Sect. B 121, 432-436 (1997).

${ }^{7}$ C. Bolis, L. Berthe, M. Boustie, M. Arrigoni, S. Barradas, and M. Jeandin, "Physical approach to adhesion testing using laser-driven shock waves," J. Phys. D: Appl. Phys. 40, 3155-3163 (2007).

${ }^{8}$ L. Berthe, M. Arrigoni, M. Boustie, J. Cuq-Lelandais, C. Broussillou, G. Fabre, M. Jeandin, V. Guipont, and M. Nivard, "State-of-the-art laser adhesion test (LASAT)," Nondestr. Test. Eval. 26, 303-317 (2011).

${ }^{9}$ R. Ecault, M. Boustie, L. Berthe, F. Touchard, L. Chocinski-Arnault, H. Voillaume, and B. Campagne, "Development of the laser shock wave adhesion test on bonded CFRP composite," Int. J. Struct. Integr. 5, 253-261 (2014).

${ }^{10}$ R. Fabbro, J. Fournier, P. Ballard, D. Devaux, and J. Virmont, "Physical study of laser-produced plasma in confined geometry," J. Appl. Phys. 68, 775-784 (1990).

${ }^{11}$ L. Berthe, R. Fabbro, P. Peyre, L. Tollier, and E. Bartnicki, "Shock waves from a water-confined laser-generated plasma," J. Appl. Phys. 82, 2826-2832 (1997).

${ }^{12}$ L. Berthe, R. Fabbro, P. Peyre, and E. Bartnicki, "Wavelength dependent of laser shock-wave generation in the water-confinement regime," J. Appl. Phys. 85, 7552-7555 (1999).

${ }^{13}$ J. Limpert, S. Höfer, A. Liem, H. Zellmer, A. Tünnermann, S. Knoke, and H. Voelckel, "100-W average-power, high-energy nanosecond fiber amplifier,” Appl. Phys. B 75, 477-479 (2002).

${ }^{14}$ J.-C. Chanteloup, H. Yu, G. Bourdet, C. Dambrine, S. Ferre, A. Fulop, S. Le Moal, A. Pichot, G. Le Touze, and Z. Zhao, "Overview of the Lucia laser program: Toward 100-joules, nanosecond-pulse, $\mathrm{kW}$ averaged power based on ytterbium diode-pumped solid state laser," Proc. SPIE 5707, 105-116 (2005)

${ }^{15}$ D. Courapied, L. Berthe, P. Peyre, F. Coste, J.-P. Zou, and A.-M. Sautivet, "Laser-delayed double shock-wave generation in water-confinement regime," J. Laser Appl. 27, S29101 (2015).

${ }^{16}$ L. Barker and R. Hollenbach, "Laser interferometer for measuring high velocities of any reflecting surface," J. Appl. Phys. 43, 4669-4675 (1972).

${ }^{17}$ P. Peyre, L. Berthe, V. Vignal, I. Popa, and T. Baudin, "Analysis of laser shock waves and resulting surface deformations in an $\mathrm{Al}-\mathrm{Cu}-\mathrm{Li}$ aluminum alloy,” J. Phys. D: Appl. Phys. 45, 335304 (2012).

${ }^{18}$ P. Peyre, L. Berthe, R. Fabbro, and A. Sollier, "Experimental determination by PVDF and EMV techniques of shock amplitudes induced by 0.6-3 ns,” J. Phys. D: Appl. Phys. 33, 498-503 (2000).

${ }^{19}$ A. Sollier, L. Berthe, and R. Fabbro, "Numerical modeling of the transmission of breakdown plasma generated in water during laser shock processing,'Eur. Phys. J. Appl. Phys. 16, 131-139 (2001). 